\section{THE FOURTH INTERNATIONAL RAIL HUMAN FACTORS CONFERENCE}

\section{5-7 March 2013, London, United Kingdom}

The Fourth International Rail Human Factors Conference took place on the 5-7 March 2013 at the CBI Conference Centre, Oxford Street, London. The Conference was jointly organised by RSSB, the University of Nottingham and Network Rail. Over 170 delegates attended from far and wide including Australia, the United States, Japan, Hong Kong and from across Europe.

The Conference was opened by Paul Zanelli, Ph.D. (Head of Research at Network Rail) and Michael Woods (Head of Operations Research, RSSB), who drew out the importance of the human factors profession in the rail industry. The programme consisted of three parallel sessions of papers (four parallel sessions on day one) which amounted to over 100 presentations over the three days. Two interactive workshops were also held including a session on the Railway Action Reliability Assessment (RARA) method, organised by Dr. Huw Gibson. The key note speakers from the United States and France opened each of the three days of the conference. The programme covered a diverse range of topics including traffic management, safety culture, competence, human reliability, metro, ERTMS, passengers and stations and track work.
Two technical visits to the London Underground training centre and the Victoria Line Service Control Centre were also organised. The conference proceedings were provided to delegates in a book called 'Rail Human Factors, Supporting reliability, safety and cost reduction' which was edited by the Nottingham University and RSSB.

The social highlights of the Conference included a drinks reception sponsored by Greenstreet Berman Ltd. and an evening dinner hosted at the Paramount restaurant on the 31st floor of the Centre Point Tower. The dinner gave delegates the opportunity to view the sights of London and mingle with old and new friends.

The researchers of the Faculty of Transport and Traffic Sciences University of Zagreb participated in the Conference, presenting the results of the research in the area of anthropological measures of tram drivers important for tram control panel design, for research within the scientific project "Cognitive Ergonomics in the Function of Traffic Safety Increase”.

Ann Mills, Ph.D., Head of Human Factors Team, Traffic Operation and Management, RSSB, London, United Kingdom Davor Sumpor, Ph.D., University of Zagreb, Faculty of Transport and Traffic Sciences, Zagreb, Croatia

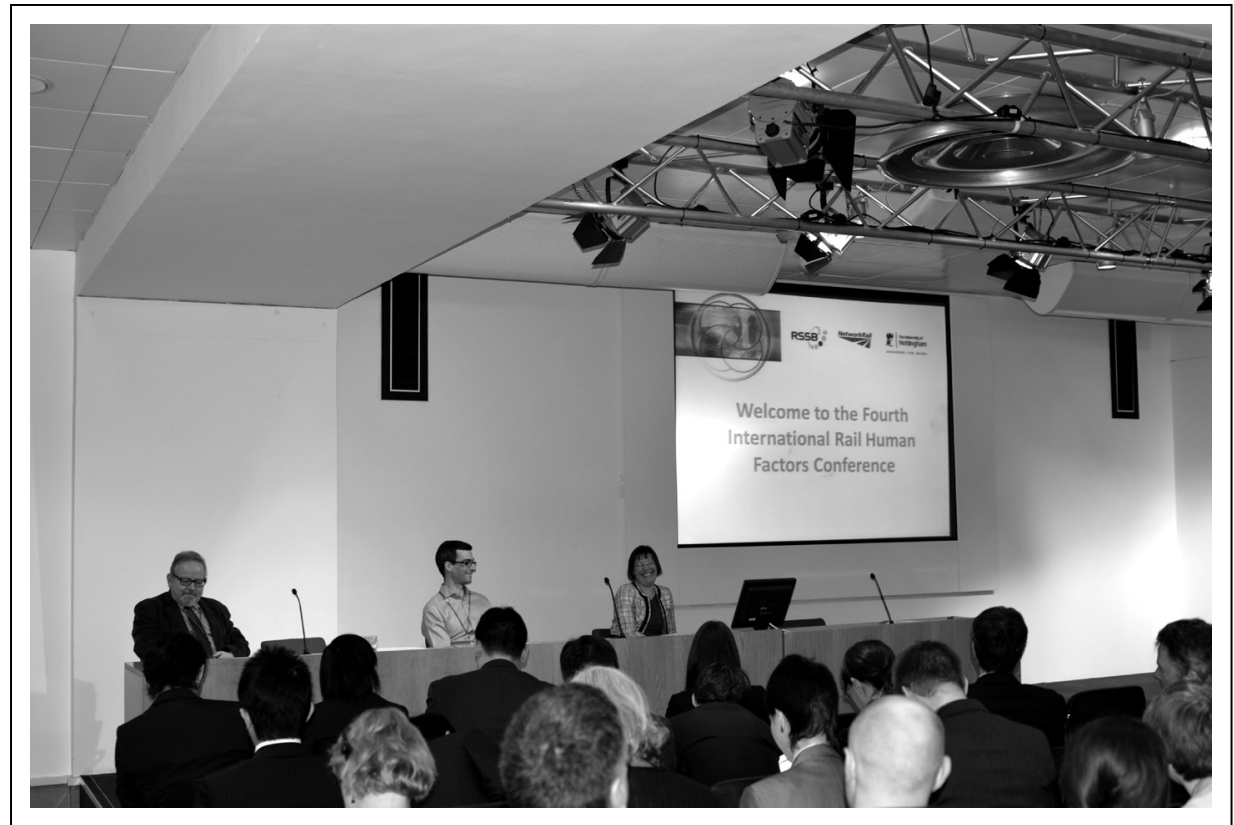

Michael Woods (Head of Operations Research, RSSB), Paul Zanelli, Ph.D. (Head of Research at Network Rail), Ann Mills, Ph.D. (Head of Human Factors, RSSB) 